\title{
Monitoring of physical education and other standards of a Whole Active School Approach and assessment of learning outcomes: a PE teacher and PE student pilot study of the EuPEO project in Germany
}

\author{
Roland Naull,"*, Stefanie Dahl ${ }^{2}$, Nils Neuber ${ }^{2}$, Michael Fahlenbock ${ }^{3}$, \\ Daniel Möllenbeck ${ }^{3}$
}

\author{
1 Willibald Gebhardt Institute, Münster, Germany \\ 2 Institute of Sport \& Exercise Sciences, University of Münster, Germany \\ 3 German PE Teacher Association \\ * Corresponding author: r.naul@wwu.de
}

\begin{abstract}
This study of assessment of learning outcomes in physical education classes including a "Whole Active School Approach" (WASA) is a part of the Erasmus+ EuPE0 project in Germany. 19 German PE teachers at $n=13$ different secondary schools (rural area $=63.2 \%$ ), cross 5 German countries with their $n=388 \mathrm{PE}$ students (average age: 15.2 years; girls: 59.4\%) were asked about their assessment of learning outcomes in PE teaching domains and the implementation of a WASA as a part of a questionnaire (European School Questionnaire (ESQ) for teachers and European Pupils Questionnaire (EPQ)). There is a clear ranking profile in the view of pupils about their assessment by PE teachers: the highest assessed criteria are social aspects like team work, respect and social relations with other class mates (85\%), followed by physical competences with health-related fitness, motor skills and sport techniques (76\%). In the ranking levels of achievements the motor domain ranked only in 4th position. Some teaching domains (social and behavioural purposes) seem to be of more importance in the view of teachers and their students than physical and motor development. Extra-curricular school sport is offered by more than $80 \%$ of the schools, but range of participation of pupils is low with around $32 \%$ assessed by teachers and up to $42 \%$ assessed by their pupils. Some other divergences in the view of teachers and pupils exist for the implementation of physical activities in recess (teachers 74\%; pupils almost 60\%) and after-school programmes (teachers about 53\%, pupils about 23\%). Data are discussed and divergences in assessment are explained in this study. Finally, a WASA to support daily physical activities does exist but really needs further support in school life.
\end{abstract}

\section{KEYWORDS}

Germany; PE teachers; PE students; learning outcome assessment; whole active school approach

DOI

$10.14712 / 23366052.2020 .2$

(C) 2020 The Authors. This is an open-access article distributed under the terms of the Creative Commons Attribution License (http://creativecommons.org/licenses/by/4.0), which permits unrestricted use, distribution, and reproduction in any medium, provided the original author and source are credited. 


\section{BACKGROUND}

There exist some different reviews about the state of the art of PE on international level. Some scholars and research consortia (Pühse \& Gerber, 2005; Bailey, 2006; Klein \& Hardman, 2008; Onofre et al., 2012a, b; Popovic et al., 2018; Naul \& Scheuer, 2020) monitored PE development likewise some international PE umbrella organizations did: ICSSPE's "World-wide Reviews" (Hardman \& Marshall, 2000, 2009); the UNESCONWCPEA Survey (2013) and the follow up of UNESCO's "Quality Physical Education Manual" for policy makers (2015). Special interest and support of advocacy was given to the development of school-based physical education in Europe also by institutions of the European Union (CDDC, CoE: Hardman, 2002, 2007; EACEA/Eurydice, 2013; EU-Expert Group, 2015; Kornbeck, 2019). Results show up to five different domains in teaching PE at school, but without identical terminology. Characterising and conceptualising these educational domains in $\mathrm{PE}$, there is a European consensus visible of at least three essential domains: physical-motor domain, psycho-social domain and mental-cognitive domain (Scheuer \& Naul, 2018).

However, all these and some other reviews and recommendations on the subject of PE did include data collection mainly of experts in PE at higher learning institutes and less on grass roots level of Head School Teachers, School Sport Coordinators, licenced PE teachers, parents or PE pupils. Such a "grass root PE study" is the Erasmus+ project "EuPEO = European Physical Education Observatory" (January 2018 up to December 2020).

\section{The EuPEO-Study}

The EuPEO-project was initiated by the Portuguese lead partner, the Faculty of Human Movement Studies (FMH) at the University of Lisbon (Onofre et al., 2018) and includes 11 partners from 8 countries (Portugal, Ireland, Germany, France, Switzerland, Czech Republic, Hungary, and Slovenia). The EuPEO-project is divided into three parts: (1) review of previously applied instruments and construction of a Country (ECQ), School (ESQ) and Pupils Questionnaire (EPQ) applied in a pilot A; (2) evaluation of the pilot A, fine tuning of the questionnaires for the two main instruments of the study, the "Manual of External Assessment" (MEA) of PE settings and the "Toolkit for Internal Monitoring" (TIM) of PE settings at school, again applied in a pilot B; (3) outcome of pilot B, preparation of the final version of the MEA and TIM instruments including dissemination to future multipliers in the 8 countries.

This paper will report on the German ESQ and EPQ studies (2018/19) with selected components and items of the curriculum flexibility dimension of each study in pilot A.

\section{The European School and Pupils Questionnaire (ESQ \& EPQ)}

As a part of the first working package of the Erasmus+ project EUPEO, a European School Questionnaire (ESQ) and a European Pupils Questionnaire (EPQ) were compiled by participating members of the project. An English version of both instruments was translated into German language by the authors of this paper. Before application of data collection, the German version of the questionnaires were piloted by PE teach- 
ers and PE students for meaning and understanding, both groups were not located at the same school.

The ESQ and EPQ were structured into dimensions. Each dimension was subdivided into components and each single component includes concrete indicators for analysis and assessment of teachers and pupils.

For instance: the ESQ is structured into six dimensions (1. character of the school context; 2 . curriculum flexibility; 3 . teacher workforce; 4 . teacher training; 5 . community partnerships and 6. facilities, equipment and resources. Consequently, e.g. dimension No. 6 has three components (6.1 facilities, 6.2 equipment, 6.3 resources). The facility component 6.1 includes four indicators: adequacy, facilities' PE curricular flexibility, access to facilities, safety and health.

The EPQ includes three dimensions (curriculum flexibility, material \& resources and community partnerships). The dimension of curriculum flexibility was structured into three components (1. physical education, 2. school sports, 3. other forms of physical activity). The component of physical education comprises five indicators: 1.1 contents, 1.2 assessment and grading, 1.3 learning outcomes, 1.4 field trips, 1.5 pedagogical principles.

This paper will address selected results of the ESQ ( $\mathrm{n}=13 \mathrm{PE}$ teachers) and EPQ ( $\mathrm{n}=388 \mathrm{PE}$ pupils) of the pilot study A at secondary schools in Germany. The results are restricted to the dimension of curriculum flexibility and their components with indicators of ESQ and EPQ.

Teachers were asked about five sub-categories which are part of a WASA (Scheuer \& Naul, 2018). These components are: Assessment criteria in PE and school sports (1) with expected and ranked learning outcome of pupils, participation in extra-curricular physical activities of pupils (2) at school; active learning of pupils in other school subjects (3), physical activities in recess time (between school lessons) of pupils (4), offer \& participation of pupils in PA after-school programmes and (5) active transportation of pupils to school. Data and results of this pilot study are pooled according to these five sub-categories of a WASA.

Data were collected between May and June 2018 for the ESQ and between January and April 2019 in case of the EPQ, both at the same schools. The data were assessed using SPSS 24.

\section{Sample}

After language control of the German issues of ESQ and EPQ with some revisions, ESQ was sent to $\mathrm{n}=19$ different head teachers/expert teachers of PE to collect data of $\mathrm{PE}$ at their school (13 secondary schools, 6 primary schools) on the six different components of the ESQ.

As figure 1 shows, the schools are located in five different German states (Brandenburg [Gransee, Löwenberg, Neuruppin, Stechlin], Baden-Württemberg [Filderstadt, Remshalden, Stuttgart, Waiblingen], Lower Saxony [Fürstenau, Hannover, Langenhagen, Weyhe], North-Rhine Westphalia [Bocholt, Langerwehe, Solingen] and Saxony-Anhalt [Sandersdorf-Brehna, Naumburg]). 


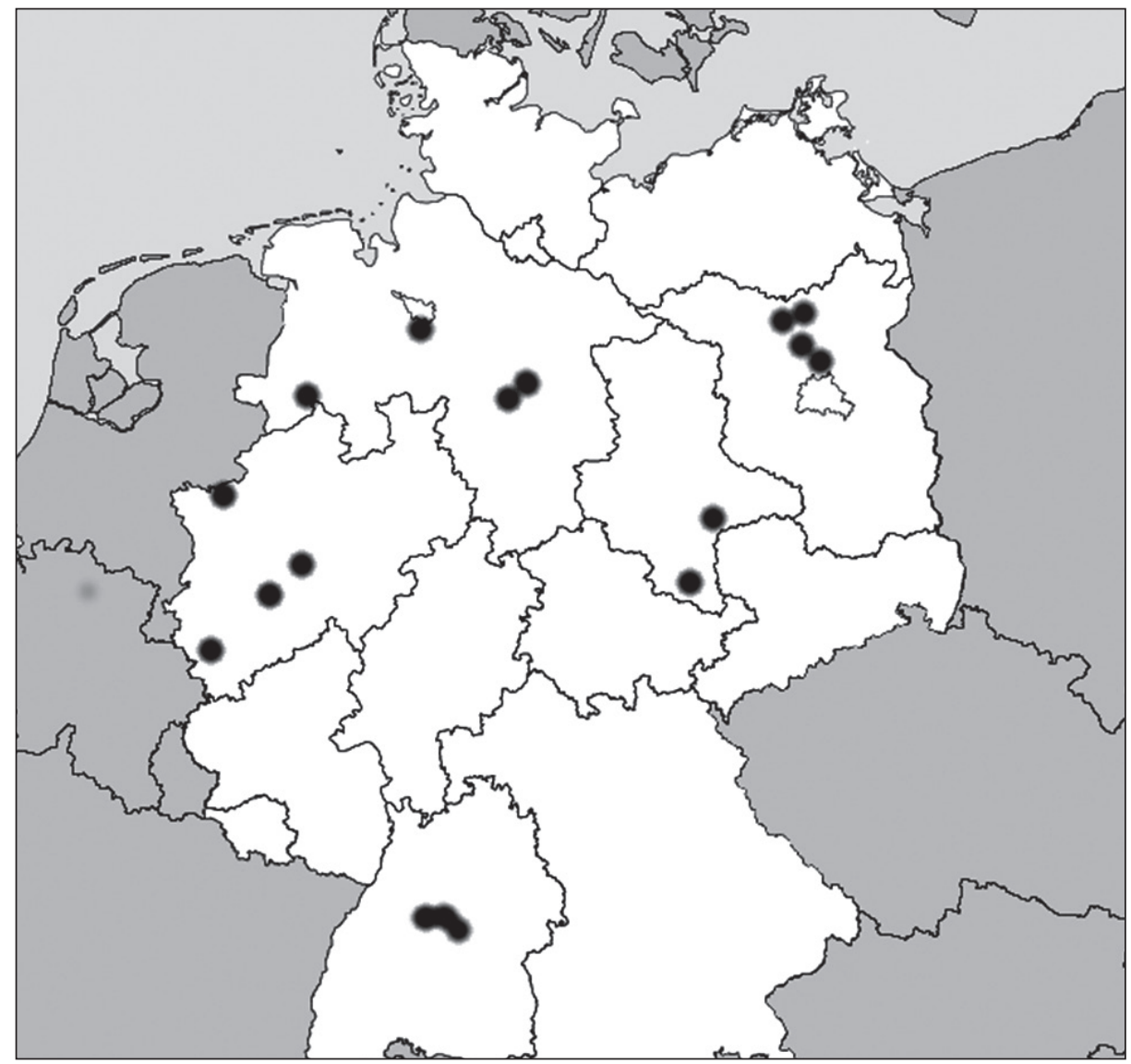

Figure 1 Location of elementary and secondary schools (ESQ and EPQ, pilot A)

500 copies of the EPQ were posted for delivery to the head teachers/PE experts at the 13 secondary schools for data collection in grades 9 and 10 at their schools. Eleven of these 13 secondary schools finally participated in the EPQ data analysis, while two schools in Lower Saxony were not able to participate anymore.

The 13 secondary schools involved in the pilot study cover six different types of the German Länder school system (rural area $=63.2 \%$ ), running form Middle School up to Upper Secondary Schools; the German Comprehensive School (5) was the most included type of school. Besides the $13 \mathrm{PE}$ teachers $\mathrm{n}=388 \mathrm{PE}$ pupils (average age: 15.2 years; girls: $59.4 \%$ ) of final grades of the schools participated in the survey. Most of the pupils $(n=198)$ attended the German Grammar School (see Table 1). The size of schools varied between 142 students (primary school) and 1.500 students (Comprehensive/Grammar School). 
Table 1 Type of secondary schools and sample sizes of teachers and pupils

\begin{tabular}{lcc}
\hline \multicolumn{1}{c}{ Type of School } & No. of schools ESQ & No. of pupils EPQ \\
\hline Middle School & 1 & 65 \\
Comprehensive School & 5 & 71 \\
Grammar School & 4 & 198 \\
Lower Secondary School & 1 & 28 \\
Community School & 1 & - \\
Upper Secondary School & 2 & 26 \\
\hline
\end{tabular}

\section{Results of physical education content areas and assessment of grading and learning outcome}

German secondary schools provide a strong games profile for their pupils in grade 9 and 10. Athletics (73.7\%) are far more given than gymnastics (51.3\%). Each second school of the sample offers fundamental movement skills and dance. Physical and sport-related knowledge and personal and social competences are targeted as indicators for PE in one out of three schools (see Figure 2).

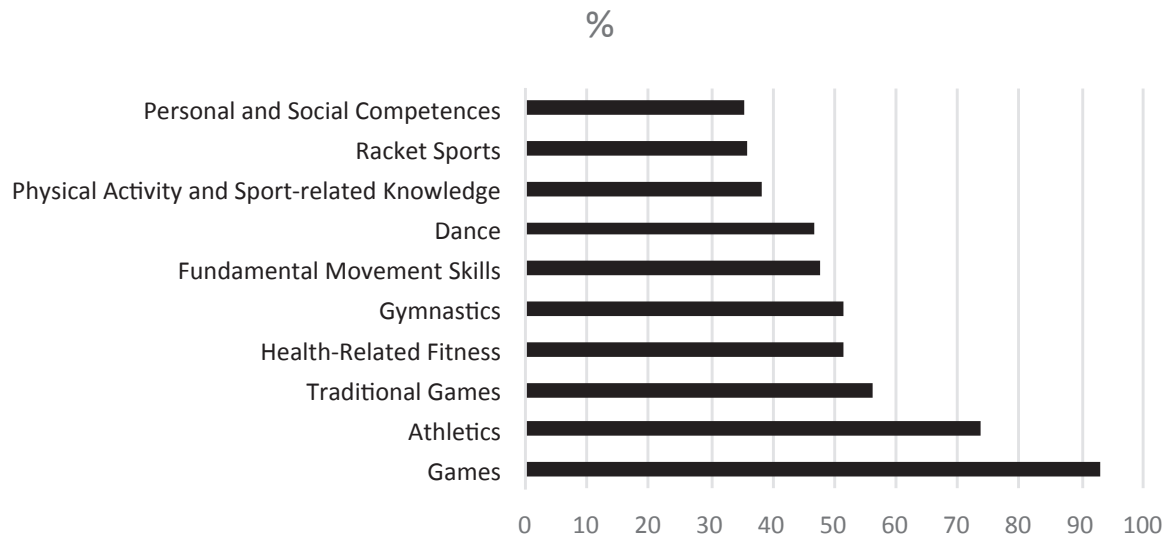

Figure 2 Contents taught in the last compulsory school year in German secondary schools $(E P Q n=388)$

Approx. $80 \%$ of the teachers agreed to apply school-based assessment criteria for grading and learning outcome of their pupils as a summative evaluation in their PE classes; almost half of them do also formative evaluation. The PE department at school is responsible for that, also to pass results to parents. Both, teachers and pupils agreed up to $50 \%$ (each second school of study) that pupils are allowed to participate in identifying criteria of assessment, more than $30 \%$ of teachers said 'No'. For the authors of this paper it is striking that only $5 \%$ of teachers apply screenings of their pupils' development in PE at the start of the school year (all results are shown in Table 2). 
Table 2 Assessment criteria items of PE in \% (ESQ $n=19 ; \mathrm{EPQ} n=388)$

\begin{tabular}{lcc}
\hline & PE Teachers & PE Students \\
\hline Criteria given at school & 78.9 & not asked (n.a.) \\
Kind of criteria (if there are criteria) & & n.a. \\
Summative evaluation & 78.9 & n.a. \\
Formative evaluation & 42.1 & n.a. \\
Screening at start of school year & 5.3 & n.a. \\
PE department responsible & 78.9 & n.a. \\
Student participation given & yes: 47.4 & 49.5 \\
& no: 31.6 & \\
Parents feedback information & 78.9 & 100 \\
\hline
\end{tabular}

Table 3 Pupils'PE assessments of learning outcome and personal achievements $(E P Q n=388)$

\begin{tabular}{lcc}
\hline & Valid \% & Mean Likert Scale \\
\hline Learning outcomes assessed on a state level & & $\begin{array}{c}\text { Personal achievements } \\
\text { (Mean; 3-point Likert Scale) }\end{array}$ \\
Social aspects (positive relations, team work, respect) & 85 & 2.4 \\
Psychological aspects (self-esteem, body image) & 28 & 1.9 \\
Physical aspects (skills, techniques, health related fitness) & 76 & 2.3 \\
Cognitive aspects (understandings, memory) & 17.2 & 2.0 \\
Kind of assessment & & Student agreement with assessment \\
& & (Mean; 5-point Likert-Scale) \\
Norm tables & 71.8 & 3.3 \\
Individual progression & 53.4 & 3.9 \\
Comparisons to other students & 43.6 & 3.3 \\
\hline
\end{tabular}

Learning outcome assessment in PE is related to a framework on regional state level in German secondary schools. There is a clear ranking profile in the view of pupils about their assessment by PE teachers: the highest assessed criteria are social aspects like team work, respect and social relations with other class mates ( $85 \%)$, followed by physical competences with health-related fitness, motor skills and sport techniques (76\%). Self-esteem, body image and other individual psychological aspect in PE is ranked with $28 \%$, followed by only $17 \%$ of cognitive items as a learning outcome (see Table 3).

As Table 3 also shows, there exist three different yardsticks for outcome measurements: physical performance levels written in norm tables are the most frequently used tool for outcome and learning assessment in the view of pupils (approx. $72 \%$ ) followed by $53 \%$ which are related with the individual progression rate of a pupil which 
is often compared and assessed to the development of other pupils in the respective class $(43 \%)$.

Pupils were further asked in how far their learning outcome aspects were achieved and in how far they agree with the three different yardsticks of their learning outcome assessments by teachers. A three point (learning outcome) and five point (agreement on yardsticks) Likert-Scale was given for personal assessment. All different aspects of learning outcome in PE were achieved (mean $=1.5)$ : the social and physical aspects scored highest (2.4 and 2.3). The most preferred yardstick of assessment was the individual progression assessment (3.9). No yardstick was disagreed on (mean $=2.5$ ), but norm tables (3.3) were much lower agreed by pupils compared with the most frequently used tool of PE teachers (see Table 3).

A more precise comparison about the different domains of achievement in learning outcome of $\mathrm{PE}$ and personal importance of the domains in the view of pupils are given in Figure 3 and 4.

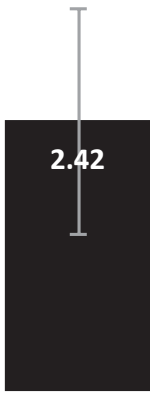

Behavioural Domain

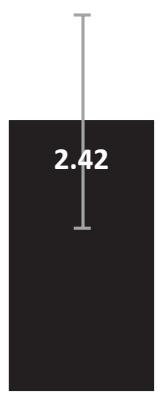

Social

Domain

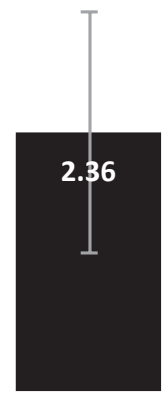

Health-Related

Fitness

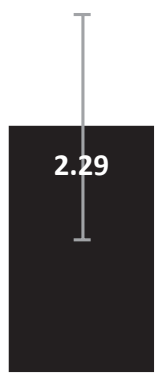

Motor

Domain

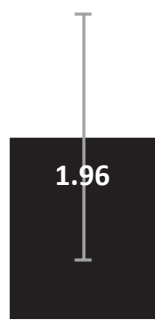

Cognitive

Domain

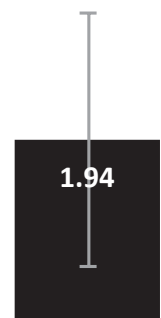

Psychological Domain

Figure 3 Ranking level of achievements of learning outcomes in PE

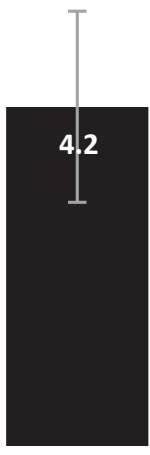

Social Domain

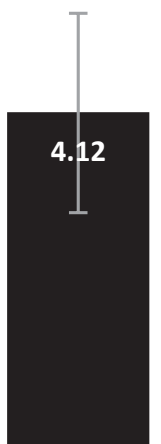

Behavioural Domain

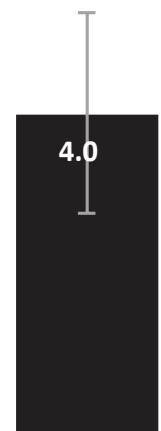

Health-Related Fitness

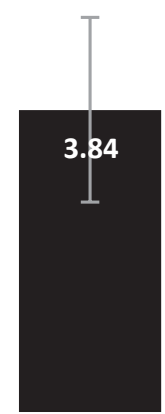

Motor

Domain

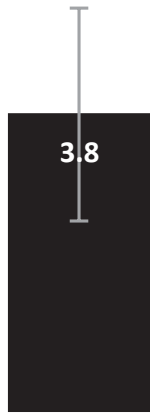

Psychological Domain

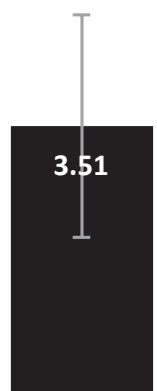

Cognitive Domain

Figure 4 Ranking level of personal importance of learning outcome in PE 
The behavioural and social domains ranked highest $(2.42 \pm 0.6$ each $)$ but only slightly before the health-related fitness $(2.36 \pm 0.6)$ and motor domain $(2.29 \pm 0.6)$ (see Figure 3).

Almost identical to the learning outcome ranking the pupils also assessed their personal importance of the different learning domains in PE except one item: the social domain and behavioural domain changed its former ranking positions; the social domain $(4.2 \pm 0.9)$ has slightly become of more personal importance than the behavioural domain $(4.12 \pm 0.9)$. It is somewhat striking that the motor domain in PE ranked only fourth position in both assessments and that two educational domains seems to be better achieved and of more relevance for the pupils than the motor and health related fitness domain in the subject of $\mathrm{PE}$.

\section{Results of Whole Active School Approach}

Beside curricular PE lessons at school, there are some more curricular, extra-curricular and co-curricular components which are part of the so-called "Whole Active School Approach" (WASA). Table 4 documents the range and status of implementation at our pilot schools in the view of PE teachers and their PE students.

Table 4 WASA assessed in \% by PE teachers $(n=19)$ and their students $(n=388)$

\begin{tabular}{|c|c|c|c|c|c|c|}
\hline & Curricular & Curricular & $\begin{array}{l}\text { Extra- } \\
\text { Curricular }\end{array}$ & $\begin{array}{l}\text { Extra- } \\
\text { Curricular }\end{array}$ & $\begin{array}{c}\text { Extra- } \\
\text { curricular }\end{array}$ & Co- curricular \\
\hline & $\begin{array}{c}\text { Regular Physical } \\
\text { Education }\end{array}$ & $\begin{array}{l}\text { Active Learning } \\
\text { in other subjects }\end{array}$ & School Sports & $\begin{array}{c}\text { Physical Activity } \\
\text { in Recess }\end{array}$ & $\begin{array}{c}\text { After-school PA } \\
\text { Programs }\end{array}$ & $\begin{array}{c}\text { Active } \\
\text { Commuting } \\
\text { to school }\end{array}$ \\
\hline $\begin{array}{l}\text { Physical } \\
\text { Education } \\
\text { Teachers }\end{array}$ & 100 & 78.9 & $\begin{array}{c}\text { Offer: } 84.2 \\
\text { Participation: } \\
31.6\end{array}$ & 73.7 & 52.6 & 36.8 \\
\hline $\begin{array}{l}\text { Physical } \\
\text { Education } \\
\text { Pupils }\end{array}$ & 100 & 30.2 & 42.0 & 59.0 & 22.7 & 30.4 \\
\hline
\end{tabular}

Teachers and pupils, both groups agreed about regular PE lessons in all types of their secondary schools (100\%). However, active learning in other school subjects is quite differently assessed: up to almost $80 \%$ of PE teachers agree about implementation of active learning in other school subjects; their students only agree up to $30 \%$. This discrepancy can be explained by the fact that PE teachers teach PE also in lower 5th and 6th grades, whereas the PE pupils are 9th and 10th graders. In higher grades active learning with movements in academic subjects is really rare and very often pupils in their age of 14 to 16 years did not experience active learning when they attended primary school classes some years before. Extra-curricular school sport is offered by more than $80 \%$ of the schools, but range of participation of pupils is low with around $32 \%$ assessed by teachers and up to $42 \%$ by their pupils. These data of low participation 
Table 5 Participation in School Sports assessed by PE teachers $(n=19)$

\begin{tabular}{lc}
\hline \multicolumn{1}{c}{ Participation and Costs } & Data $\%$ \\
\hline Participation rate overall & $15-20 \%$ by $21 \%$ of teachers \\
& $30 \%$ by another $21.1 \%$ \\
Participation of different groups & \\
Girls & $10.5 \%$ \\
Special need groups & $10.5 \%$ \\
Low SES groups & $10.5 \%$ \\
Immigrants & $5.3 \%$ \\
Extra fees to pay & $42.1 \%$ not at all; $42.1 \%$ yes, for special offers \\
\hline
\end{tabular}

All values $=\%$ (including missing values)

range in extra-curricular school sport really coincide with other German school sport studies in the last 20 years (Spengler et al., 2016; Naul et al., 2020). Some other divergences in the view of teachers and pupils exist for implementation of physical activities in recess (teachers 74\%; pupils almost 60\%) and after-school programmes (teachers about $53 \%$, pupils about $23 \%$ ). The explanation is: not all pupils, particularly girls in their age of 14 to 16 years, really like physical activities to exercise in recess time; other participation data of pupils' engagement in after-school sport programmes reveal that only half of the pupils or even less really attend all-day schools with sport after-school programmes (Neuber et al., 2015; Kuritz et al., 2016). Finally, new co-curricular offers with active commuting to school are on development in Germany. Almost one out of three schools in this study offers "walking bus", "save biking" etc. for their pupils.

Data of participation of pupils in school sports document in our pilot well known results of previous German studies (Spengler et al., 2016). The results in Table 5 show an ambivalent picture between secondary schools: some schools (here about 20\%) report an average participation rates of over $30 \%$, whereas another approx. $20 \%$ of schools only report on 15 up to $20 \%$ of pupils who participate in school-based school sport offers. In the ages of 14 to 16 years, girls, adolescents with special needs, children form low SES groups and particularly immigrants participate on a low (about 10\%) and very low level (5\%) in extra-curricular school sports.

Table 6 Participation in School Sport assessed by PE Pupils $(\mathrm{n}=388)$

\begin{tabular}{lccccccc}
\hline \multirow{2}{*}{$\begin{array}{c}\text { Physical } \\
\text { Education } \\
\text { Students }\end{array}$} & \multicolumn{2}{c}{ Participation } & \multicolumn{2}{c}{ No. of activities } & \multicolumn{3}{c}{ Time } \\
\cline { 2 - 7 } & Yes & & \multicolumn{2}{c}{ Times per week } & \multicolumn{2}{c}{ Minutes per week } \\
\cline { 2 - 7 } & $\%$ & mean \pm SD & Min/Max & mean \pm SD & Min/Max & mean \pm SD & Min/Max \\
\hline $\begin{array}{l}\text { Secondary } \\
\text { School }\end{array}$ & 42.0 & $2.55 \pm 2.57$ & $0 / 13$ & $1.36 \pm 1.01$ & $0 / 7$ & $116.87 \pm 106.7$ & $0 / 600$ \\
\hline
\end{tabular}


Some more precise data about extra-curricular school sports are reported by PE pupils, as shown in Table 6 : in their view $42 \%$ are involved in extra-curricular school sport activities. However, the ambivalences already documented by their PE teachers are also visible here: there are secondary schools without any physical activities (0) in extra-curricular school sports and minimums of times and minutes of school sports per week are zero! On the other side means of activities, times and minutes per week ranges between 2.5 different physical activities, 1.36 times and about 117 minutes. But also some sport minded schools are a part of our pilot sample which offers up to 13 different physical activities, seven times a week and with a maximum of 600 minutes.

\section{DISCUSSION}

Caution is needed to interpret data of this first EuPEO pilot study (A) as very typical results about teaching, monitoring and assessment outcomes of PE in German secondary schools. However, some results do really coincide with previous surveys, some do not. Other data of items e.g. for the WASA cannot be compared, because they are unique and have never been collected as a set of items before and can give only a first insight.

Across the five different German countries involved in this pilot study of assessment criteria in PE, school-based criteria seem to be the most spread, mainly for summative assessment and less for formative assessment. Only half of the sample of PE teachers agreed that their pupils can participate in identifying assessment criteria. Assessment criteria do either not exist or are not applied to screen the development of pupils at the beginning of a school year which underpins the lower importance of formative evaluation in $\mathrm{PE}$.

For PE teachers and for their pupils learning outcome of $\mathrm{PE}$ is ranked highest for social and behavioural aspects; lowest for cognitive aspects. For the authors of this study it is striking that even pupils ranked the motor/fitness domains in PE not in the premier level. This result contradicts previous results of the so-called "DSB Sprint Study" (2006, p. 121). In the Sprint-study students of comparable age groups ranked physical fitness and the motor domain as their premier domain in physical education and behavioural domain only in fourth position. The pupils in this EuPEO-study seem to be more in line with assessment criteria of their PE teachers and controversy to their counterparts almost 15 years ago in the Sprint study. PE teachers in this study ranked applied norm tables of motor and physical performances as the most relevant format of assessment in PE which application is merely confirmed by their students. However, these students would prefer instead of norm tables measurements of their individual progress of development during a term or a semester. But almost without screening at the start of the term or semester by PE teachers (only $5 \%$ do), this type of measurement is impossible to apply.

PE students ranked learning outcome of the social and behavioural domain in physical education teaching at the most dominant one but also as the most important one in their personal perspective. There seems to be no contradiction about the rankings of PE domains between teaching in the subject of PE and about the pupils' assessed importance of individual outcome in PE. Whether this is a new trend of priority of 
domains and conformity in PE learning and outcome on which teachers and students both groups agree, cannot finally be decided and needs further studies. But definitely adolescents of today view their subject of PE differently with other priorities and learning outcomes to achieve than their counterparts of the 2000s did.

The WASA seems to be implemented in German secondary schools, but on a small level which still needs to be improved. Active learning in other subjects is more restricted to lower grades (primary schools) than to higher grades in secondary schools. Physical activities in recess must be improved at schools if a daily load of health enhanced physical activities should be achieved ( 60 minutes). The low percentages of students who attend sport courses as after-school offers (approx. 23\%) is linked with the type and amount of schools and pupils which represent the German Grammar School (Gymnasium: 4 teachers, 198 pupils) where open all-day schools are less implemented compared to other types of secondary schools. Typical ambivalences between schools exist for extra-curricular school sport regardless of the type of the school. There exists a typical gap between normal schools, sport-friendly schools and really sport-minded schools in our sample. Too many PE students do not attend school sports which lowers the outcome for achieving an active lifestyle.

\section{CONCLUSION}

Results of the ESQ and EPQ Study (pilot A) here are only findings of a small pilot study which must be approved and confirmed by further investigations like pilot B of the EuPEO-project. Some data underpin almost identical assessments between PE teachers and their PE students but also indicate some differences in application of tools to monitor and to assess learning outcomes of PE. A WASA for different physical activities does exist but really needs further support particularly by implementation of open all-day schools on secondary school level which can support the extension of active breaks in recess and other co-curricular efforts e.g. active commuting to school.

\section{REFERENCES}

Bailey, R. (2006). Physical Education and Sport in Schools: A Review of Benefits and Outcomes. Journal of School Health, 76(8), 397-401.

Deutscher Sportbund (Ed.) (2006). Die DSB-Sprint-Studie. Eine Untersuchung zur Situation des Schulsports in Deutschland. Aachen: Meyer \& Meyer.

EACEA/Eurydice (2013). Physical education and Sport at School in Europe. Eurydice Report. Luxembourg: Publication Office of the European Union.

EU-Expert Group on Health-enhancing physical activity (2015). Recommendations to encourage physical education in schools, including motor skills in early childhood, and to create valuable interactions with the sport sector, local authorities and the private sector. Brussels: EC.

Hardman, K. (2007). Current situation and prospects for physical education in the European Union. Brussels: European Parliament.

Hardman, K., \& Council of Europe Committee for the Development of Sport (CDDS) (2002). Report on School Physical Education in Europe. Strasbourg: Council of Europe.

Hardman, K., \& Marshall, J. (2000). World-wide survey of the state and status of physical education. Manchester: University of Manchester. 
Hardman, K., \& Marshall, J. (2009). Second World-wide Survey of school physical education. Berlin: ICSSPE.

Klein, G., \& Hardman, K. (2008). L'éducation physique et l'éducation sportive dans l'Union européenne. Tome 1 et tome 2. Paris: Revue eps.

Kornbeck, J. (2019). Die Konsolidierung des Politikfeldes Sport durch die Europäische Kommission vom WADA-Austritt bis zum Inkrafttreten des Vertrages von Lissabon. Köln: DSHS Diss.

Kuritz, A., Dinkelacker, M., \& Mess, F. (2016). Bewegung und Sport in Ganztagsschulen: Eine systematische Literaturanalyse zum aktuellen Forschungsstand in Deutschland. Sportwissenschaft, 46(3), 162-178.

Naul, R., \& Scheuer, C. (Eds.) (2020). Research on Physical Education and School Sport in Europe. Aachen: Meyer \& Meyer.

Naul, R., Aschebrock, H., Niehues, D., \& Utesch, T. (2020). Germany: home of curricular and extra-curricular school sport. In: Naul, R., \& Scheuer, C. (Eds.), Research on Physical Education and School Sport in Europe. Aachen: Meyer \& Meyer.

Neuber, N., Kaufmann, N., \& Salomon, S. (2015). Ganztag und Sport. In: Schmidt, W. et al. (Eds.), Dritter Deutscher Kinder- und Jugendsportbericht (pp. 416-443). Schorndorf: Hofmann.

Onofre, M., Marques, A., Moreira, A., Holzweg, M., \& Scheuer, C. (2012a). Physical education and sport in Europe: From individual reality to collective desirability (part 1). International Journal of Physical Education, 49(2), 11-35.

Onofre, M., Marques, A., Moreira, A., Holzweg, M., \& Scheuer, C. (2012b). Physical education and sport in Europe: From individual reality to collective desirability (part 2). International Journal of Physical Education, 49(3), 17-31.

Onofre, M., Costa, J., Naul, R., Repond, R., Scheuer, C., \& Holzweg, M. (2018). How to know more about physical education and school in Europe: EuPEO an project from EUPEA. In: Scheuer, C., Bund, A., \& Holzweg, M. (Eds.), Changes in Childhood and Adolescence: Current Challenges for Physical Education (pp. 97-99). Berlin: Logos.

Popovic, S., Antala, B., Bjelica, D., \& Gardasevic, J. (Eds.) (2018). Physical Education in Secondary Schools: Researches - Best Practices - Situations. Niksic: Faculty of Sport and Physical education of University of Montenegro, Montenegrin Sports Academy and FIEP Europe.

Pühse, U., \& Gerber, M. (2005). International Comparison of Physical Education. Concepts, Problems, Prospects. Oxford: Meyer \& Meyer.

Scheuer, C., \& Naul, R. (2018). The vision and mission of CEREPS, a European Council of Research in Physical Education and Physical Activity. In: Scheuer, C., Bund, A., \& Holzweg, M. (Eds.), Changes in Childhood and Adolescence: Current Challenges for Physical Education (pp. 64-66). Berlin: Logos.

Spengler, S., Mess, F., \& Woll, A. (2016). Sportunterricht und außerunterrichtlicher Schulsport in Deutschland heute - Eine Analyse ausgewählter Strukturdaten. Zeitschrift für Soziologie der Erziehung und Sozialisation, 36(4), 341-356.

UNESCO (2015). Quality Physical Education. Guidelines for Policy-Makers. Paris: Unesco. UNESCO-NWCPEA (2013). World-wide Survey of School Physical Education. Final Report. Paris: Unesco. 